\title{
HPLC Method Validation for Simultaneous Determination of Three Mycotoxins from Corn Seeds ${ }^{\dagger}$
}

\author{
Augustin Curticapean, ${ }^{\text {a }}$ Felicia Toma, ${ }^{\text {a }}$ Monica Tarcea, ${ }^{a}$ Manuela Curticapean, ${ }^{\text {a, } *}$ \\ Victor Samarghitan, ${ }^{\mathrm{a}}$ Ioan Aurel Pop, ${ }^{\mathrm{b}}$ and Alin Gulea ${ }^{\mathrm{b}}$ \\ ${ }^{a}$ University of Medicine and Pharmacy, 38 Gh. Marinescu Street, RO-540139 Târgu-Mures, Romania \\ ${ }^{\mathrm{b}}$ S.C.D.C.B. Tg-Mures, Str. Principala 1227, RO-547530 Sangeorgiu de Mures, Romania
}

RECEIVED OCTOBER 21, 2010; REVISED MAY 12, 2011; ACCEPTED MAY 16, 2011

\begin{abstract}
A new HPLC optimized method for simultaneous determination of some mycotoxins by separation and using a Dionex UltiMate3000 modular system, with multichannel UV detector was developed and validated. The method optimization was performed to determine simultaneously, several relevant mycotoxins from corn seeds that were stored over 8 months. The mycotoxins selected for quantification were: aflatoxin B1, ochratoxin A and zearalenone. They were selected due to their high concentration in the fodder. For the development stages of the HPLC method, it was introduced an internal standard to have accurate results. Taking into account that the analytes should be extracted from the complex matrix they reside, an extraction procedure was performed, using organic solvents, and the selection after repeated tests demonstrated the best capacity for ethyl acetate. The recovery is about $60-70 \%$ after the extraction process also there is a good preconcentration $(\times 2.5)$ of the analytes and the internal standard for their quantification.

The limit of quantification (LOQ) obtained by chromatographic parameters optimization, for aflatoxin B1 and ochratoxin A were about 3-5 $\mu \mathrm{g} \mathrm{kg}^{-1}$ and $14.4 \mu \mathrm{g} \mathrm{kg}$-1 for zearalenone of raw biological material, making these values lower than those accepted by the actual normatives and regulations. (doi: $10.5562 /$ cca1788)
\end{abstract}

Keywords: method validation, mycotoxins, corn seeds analysis

\section{INTRODUCTION}

The safety of humans concerning the foodstuff, become one of the most important direction in the quality of life protection. To ensure all the elements contributing to the consumer's protection and to the products quality, there would be necessary to develop new control methods, as simple as could be, low resources consumption, but usable in ordinary conditions. One of the most important requests is to advancingly eliminate the sources of toxins appearing in the foodstuff composition. Some of these sources are the fungi species producing mycotoxins, being found in most of the vegetal foodstuff products that were stored under improper conditions. But, even worse is that we can find their metabolites in the animal foodstuff after improper feeding with infested fodder. Mycotoxins are natural secondary metabolism products of mould fungi, which are part of the foodstuff contaminants as a result of their toxic effect. ${ }^{1}$ The danger of mycotoxins is to be found in their chronically toxic properties of carcinogenicity, mutagenicity, and teratogenicity. Acute poisoning with symptoms like vomiting and diarrhoea are only observed in toxins, which belong to the group of the trichothecenes. The mycotoxins are absorbed by animals via their fodder and partly transmitted to animal foodstuffs (meat, eggs, milk). As a matter of principle, foodstuffs matured with mould fungi such as cheese and cooked meat as well as enzymes generated with mould fungi, vitamins, and many more can be affected. The most important of the about 300 known mycotoxins are aflatoxins, citrinin, patulin, ochratoxin $\mathrm{A}$, fumonisin and trichothecene (nivalenol, desoxynivalenol, T2-toxin, HT2-toxin) and zearalenone.

In agricultural production, considerable losses in yield, and quality are caused all over the world by mould fungus infections. ${ }^{2}$ Above all, grain, oil seeds, coffee, fruit, vegetables, and spices are affected. In more moderate climatic zones, it is mainly fungi of the Fusarium species, which attack maize and grain. The measures for intensification and rationalization in agriculture favor the propagation of the Fusarium fungi.

\footnotetext{
$\uparrow$ Presented at the $10^{\text {th }}$ International Symposium and Summer School on Bioanalysis within the CEEPUS Network CII-HU-001004-0910, Zagreb, Croatia, July 2010.

* Author to whom correspondence should be addressed. (E-mail: manuela_claudia@yahoo.com)
} 
The Fusarium toxins formed by them include the large group of the trichothecenes, the fumonisins, and zearalenone. The representatives of the B-trichothecenes desoxynivalenol and nivalenol are frequently found mainly on grain. The A-trichothecene, T2-toxin, and HT2-toxin are proven above all in oats. Aflatoxins (B1, B2, G1, G2) are exclusively formed by Aspergillus flavus and Aspergillus parasiticus cultures, which prosper particularly well with higher temperatures and air humidity. All examinations up to now indicate that Aflatoxin B1 is the main toxin, particularly contaminated foodstuff's being corn, peanuts, hazel nuts, almonds, pistachios, walnuts, dried fruit and spices. ${ }^{3-5}$

Ochratoxin A is a chlorinated natural material, and can be formed by Aspergillus and Penicillium sp. on practically all foodstuffs, particularly during storage. Most fungi producing ochratoxin A can form further mycotoxins such as citrinin and penicillin acid. With an $\mathrm{LD}_{50}$ of $1 \mathrm{mg} / \mathrm{kg}$ in dogs and $0.62 \mathrm{mg} / \mathrm{kg}$ in pigs, ochratoxin $\mathrm{A}$ has a highly acute toxicity. In chronic consumption, it has a damaging effect on the kidneys and the immune system, also caused cancer in animal tests. ${ }^{4-6}$

Zearalenone is an estrogenically active mycotoxin, which is formed by various species of Fusarium, preferred substrate being maize and oats, and is formed by development of the fungus, present above all in grain with large amounts of fungus. Higher contents are found in maize as a rule, as removal of strongly attacked corns is not so effective as in bread grain. Zearalenone is not acutely toxic, but its carcinogenic effect is assumed. ${ }^{7}$ The appearance of the advanced materials used for the treatment of infested natural products, is dependent on the control methodology and on the performed analyses for biological infested samples. ${ }^{8}$ Many simple or macromolecular chemical compounds were discovered then proposed for usage for prevention and treatment of the effects produced by fungi development. ${ }^{9-12}$

The late published data show that many HPLC methods for determination of some mycotoxins, from around 400 known types, ${ }^{1}$ are using ultra detectors as mass spectrometry, ${ }^{13,14}$ fluorescence, ${ }^{15}$ matrix solidphase dispersion (MSPD) coupled with HPLC ${ }^{16}$ etc. Their performance is fully exploited to obtain very low limits of quantification, but on the other hand, these systems are quite expensive and require a high trained specialist and strictly controlled environment.

Analysis and quantification of the naturally produced mycotoxins respect mostly the principle of single toxin determination, our goal having the main idea of simultaneous determination for several mycotoxins by a single HPLC injection analysis in a simple modular system. The biggest task for the newly developed method was the simultaneous quantification of three mycotoxins by a single injection and individually recording of each mycotoxin on separate channel of the UV detector. The main reason of choosing this path is the known fact that most of the fungi produce more than one mycotoxin in the same time, so separate analysis for each mycotoxin in the individual infested samples would be extremely expensive.

\section{EXPERIMENTAL}

A new HPLC optimized method for simultaneous determination of some mycotoxins by separation and using a Dionex UltiMate3000 modular system having an UV detector with multiple channel recording. was developed. The method optimization was performed to determine simultaneously, by using an ordinary system, several relevant mycotoxins from corn seeds that were stored over 8 months. The mycotoxins selected for quantification were: aflatoxin B1, ochratoxin $\mathrm{A}$ and zearalenone. They were selected due to their high concentration in the fodder. For the development stages of the HPLC method, it was introduced an internal standard to have accurate results. Respecting the precision and accuracy of the GLP regulations, preparation of the standard and QC samples was performed with a unique standard sample during all the validation period, respecting the extraction stage as for all the unknown samples. The measurements for the QC samples were performed at the beginning of each working day and respecting the full GLP procedure for a method validation. For the corn samples preparation, the liquid-liquid extraction with ethyl acetate was used, than re-elution with the mobile phase A produced the aliquot samples for HPLC determinations. The stages during extraction procedures were: smashing the seeds and sorting the resulting raw biological material, then shaking for 30 min with pure ethyl acetate followed by a centrifugation at $5000 \mathrm{rpm}$. The organic extract was evaporated at $50{ }^{\circ} \mathrm{C}$ for $75 \mathrm{~min}$ and the dry samples were re-eluted with mobile phase $\mathrm{A}$ in order to be injected into the HPLC system.

\section{Materials}

Mycotoxins used in the validated method were purchased from Fermentek, Israel: Aflatoxin B1 $\left(\mathrm{C}_{17} \mathrm{H}_{12} \mathrm{O}_{6}\right), M=312.3 \mathrm{~g} \mathrm{~mol}^{-1}$ (Figure 1a); ochratoxin A $\left(\mathrm{C}_{20} \mathrm{H}_{18} \mathrm{ClNO}_{6}\right), M=403.8 \mathrm{~g} \mathrm{~mol}^{-1}$ (Figure 1b); zearalenon $\left(\mathrm{C}_{18} \mathrm{H}_{22} \mathrm{O}_{5}\right), M=318.4 \mathrm{~g} \mathrm{~mol}^{-1}$ (Figure 1c); phenacetin (Internal Standard, $\mathrm{C}_{10} \mathrm{H}_{13} \mathrm{NO}_{2}$ ), $M=179.2 \mathrm{~g} \mathrm{~mol}^{-1}$ (Figure 1d).

\section{Reagents and Solvents}

The solvents for obtaining the mobile phase and the mixture of the buffer eluent $\mathrm{A}$, acetonitrile and methanol, were purchased from Merck KGaA (LiChrosolv Gradient grade for liquid chromatography). Ortho-phosphoric acid $\left(\mathrm{H}_{3} \mathrm{PO}_{4}, w=85 \%\right)$, dipotassium 


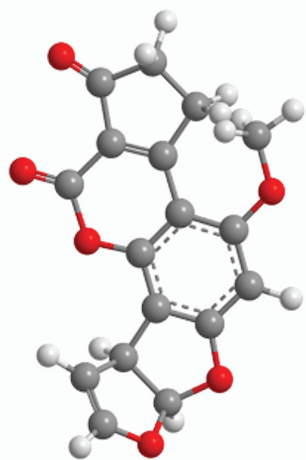

a

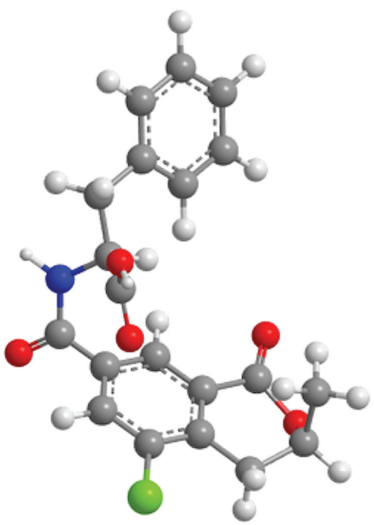

b

Figure 1. Molecular structures of the analyzed chemical species.

phosphate $\left(\mathrm{K}_{2} \mathrm{HPO}_{4}\right)$, potassium hydroxide $(\mathrm{KOH})$ and ethyl acetate (ACET) were also purchased from Merck $\mathrm{KGaA}$ as "Pro Analysi" quality. Triethylamine (TEA "For Synthesis") was purchased from Merck Schuchardt OHG. Pure water was produced by Barnstead EasyPure (pure water quality $0.055 \mu \mathrm{S}$ at $25^{\circ} \mathrm{C}$ ).

\section{Instrumentation and Devices}

An HPLC modular system DIONEX Ultimate 3000 having Chromeleon 6.8 SP7 package was used with an UV detector with possibility of four channels simultaneous recording. The system was completed with a DIONEX column type Acclaim $120 \mathrm{C} 18,150 \times 4.6 \mathrm{~mm}$, $3 \mu$, with a pre-column $\mathrm{C} 1810 \times 4.6 \mathrm{~mm}$.

For weighting it was used a Kern ABJ 220-4M analytical balance, and for mixing the samples a Zipper GmbH CAT S20 mechanical shacker. Also, for the samples separation in the extraction stages, centrifugation was performed with a laboratory centrifuge Centurion Scientific Ltd. K240. In the evaporation of the samples extracted, the rotational vacuum evaporator Christ GmbH RVC 2-25 was used. The mobile phases were ultrasonicated with an Elma TransSonic Digital S bath, and the laboratory vortex Falc Instruments Mix 10 has performed the re-elution of the evaporated samples.

\section{Optimized Validated Method}

High performance liquid chromatography method with multiple solvent gradient, was used for separation, and quantification of the selected mycotoxins and internal standard, and during each injection analysis, the in-line regeneration of the column was applied. ${ }^{18,19}$ The optimization process was conducted to have a full simultaneous determination of the three analytes and the internal standard, by parallel recording of the UV signals for each compound, at its own maximum wavelength absorption (aflatoxin $\mathrm{B}^{20}$ at $362 \mathrm{~nm}$, ochratoxin $\mathrm{A}^{21}$ at

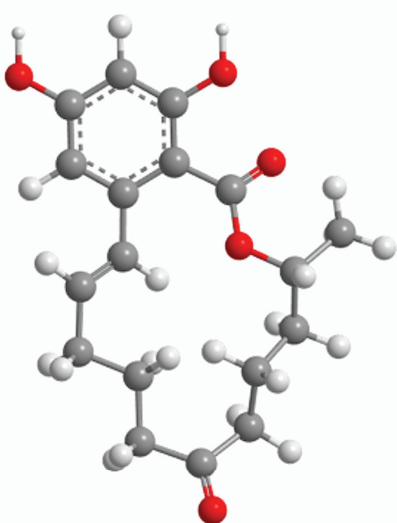

c

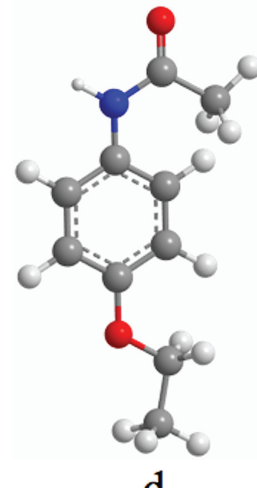

d
$215 \mathrm{~nm}$, zearalenone $\mathrm{e}^{22}$ at $236 \mathrm{~nm}$, and internal standard at $245 \mathrm{~nm}$ ). The mobile phase gradient applied contains the eluent mixture: $(\mathrm{A})+(\mathrm{B})+(\mathrm{C})$ under a complex gradient scheme (Figure 2). The components of the mixture were added as follows: (A) phosphate buffer mixture (composition for $1 \mathrm{~L}$ : pure water $650 \mathrm{~mL}$, acetonitrile $300 \mathrm{~mL}$, methanol $50 \mathrm{~mL}, 10 \mathrm{mM} \mathrm{K}_{2} \mathrm{HPO}_{4}$, TEA, $\mathrm{H}_{3} \mathrm{PO}_{4}$, corrected to $\mathrm{pH}=3.0$ ); (B) acetonitrile; (C) methanol. Mobile phase flow at $1.0 \mathrm{~mL} \min ^{-1}$ and 165 bar pressure and $25^{\circ} \mathrm{C}$ in column oven. The table of the gradient contains 3 eluents (A, B and C), and they are specifically mentioned what they content, because mobile phase A as buffer, already contains some acetonitrile and methanol, though these solvents are used later to enrich the washing and regeneration of the column after $14.8 \mathrm{~min}$ (as added solvents). The optimized method contains a very short input with organic solvents to reduce the retention time for the second and third analyte, all these till the limit of stable and reproducible results for good resolution of sharp peaks.

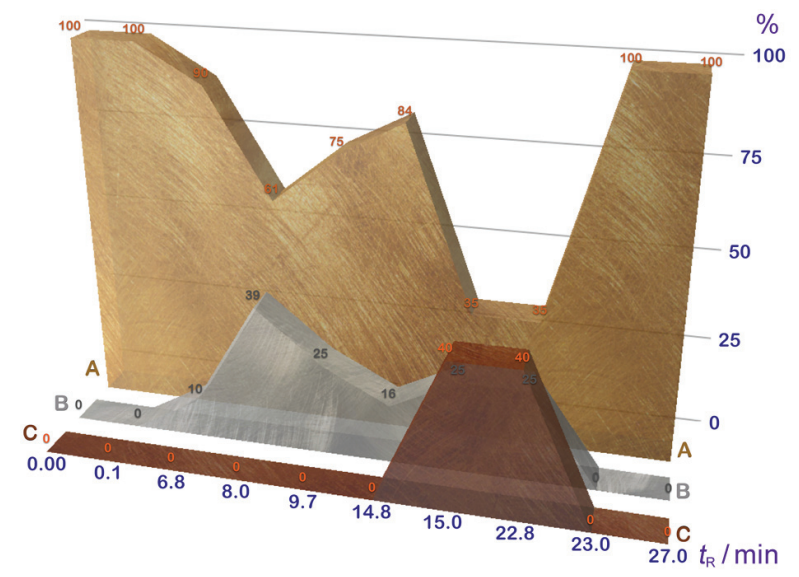

Figure 2. Gradient for simultaneous HPLC quantification of 3 mycotoxins. 


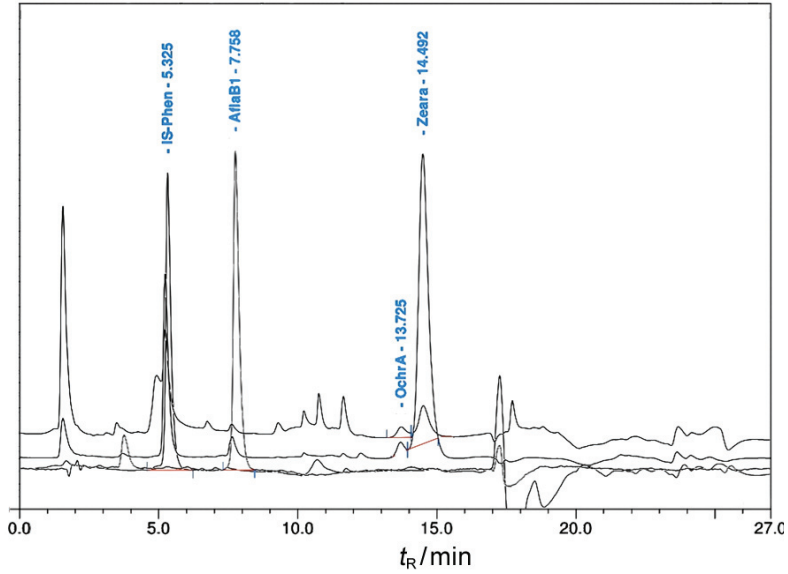

Figure 3. Overlaied individual recorded chromatograms for each mycotoxin and I. S.

\section{RESULTS AND DISCUSSION}

Retention times of the analytes are shown on the recorded chromatograms (Figure 3), and they were: for internal standard $t_{\mathrm{R}}=5.4 \mathrm{~min}$, for aflatoxin $\mathrm{B} 1 t_{\mathrm{R}}=7.7$ min (Figure 4), for ochratoxin A $t_{\mathrm{R}}=13.9 \mathrm{~min}$ (Figure 5) and for zearalenone $t_{\mathrm{R}}=14.9 \mathrm{~min}$ (Figure 6). The lower limits of quantification LOQ for the analyzed species were determined with the following values: $2.88 \mu \mathrm{g} \mathrm{kg}^{-1}$ aflatoxin B1, $2.88 \mu \mathrm{g} \mathrm{kg}^{-1}$ ochratoxin A respectively $14.4 \mu \mathrm{g} \mathrm{kg}^{-1}$ zearalenone and the records have respected the imposed conditions required by the GLP regulations (meaning that relative standard deviation should not exceed $\pm 20 \%$ also the bias in the same domain). ${ }^{23,24}$ The quantification limits that were published and reached with complex instruments are in a large range between $0.25 / 16 \mu \mathrm{g} \mathrm{kg}^{-1}$ aflatoxin $\mathrm{B} 1,{ }^{15-18} 0.25 / 8.0$ $\mu \mathrm{g} \mathrm{kg}^{-1}$ ochratoxin $\mathrm{A},{ }^{15-17} 10 / 40 \mu \mathrm{g} \mathrm{kg}^{-1}$ for zearalenone, ${ }^{15,25}$ mostly depending not only on the performance of the instruments, but on the extraction procedure applied for each type. Comparing our limits of quantification mentioned above for the three mycotoxins, one can see that they are in the ranges of these values presented lately by other groups, even we used a simple HPLC system.

The precision of the method that was validated meets the conditions of having the relative standard deviation (SD) of the measured quality control (QC) samples concentrations between $\pm 15 \%$ for intra-day and between-days assay. The SD values obtained were from 5.662 to 12.803 in the intra-days assay and from 0.258 to 12.803 in the between-days assay for aflatoxin B1, respectively from 0.568 to 7.866 in the intra-day assay and from 0.049 to 8.918 in the between-days assay for the ochratoxin A analyte, and finally from 1.549 to 11.509 in the intra-day assay and from 1.304 to 12.129 in the between-days assay for zearalenone. The accuracy of the method that was validated also meets the con-

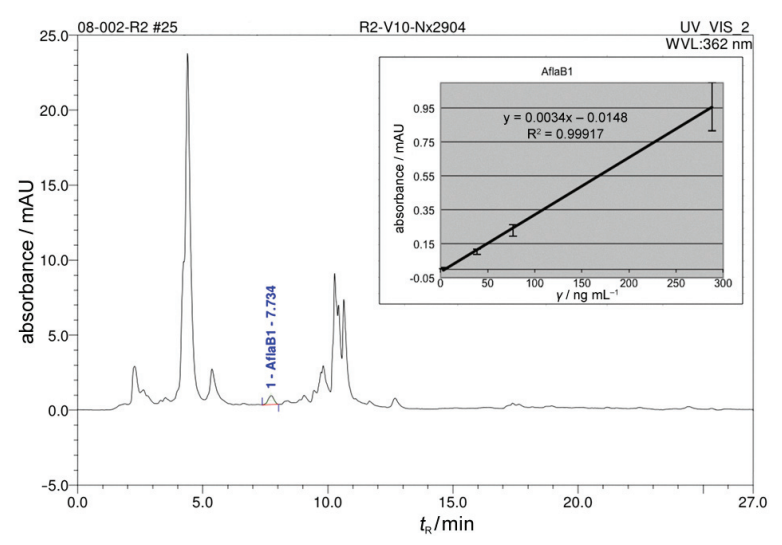

Figure 4. Overlaied chromatogram with calibration curve for aflatoxin B1.

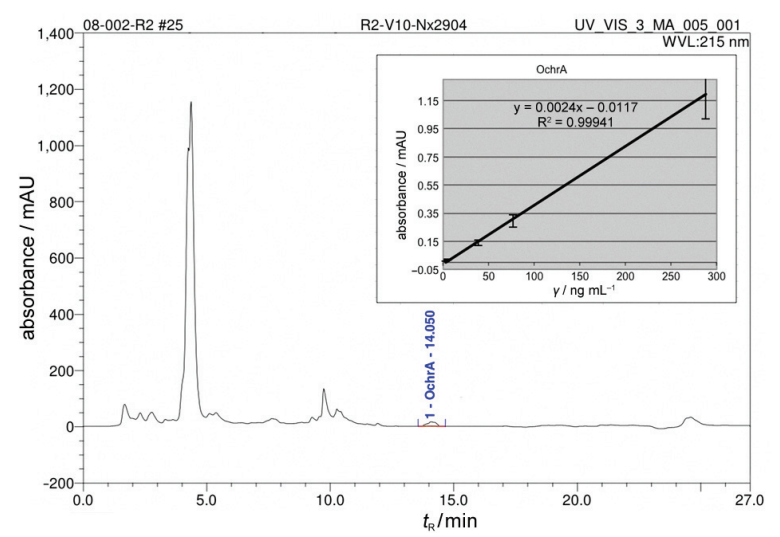

Figure 5. Overlaied chromatogram with calibration curve for ochratoxin A.

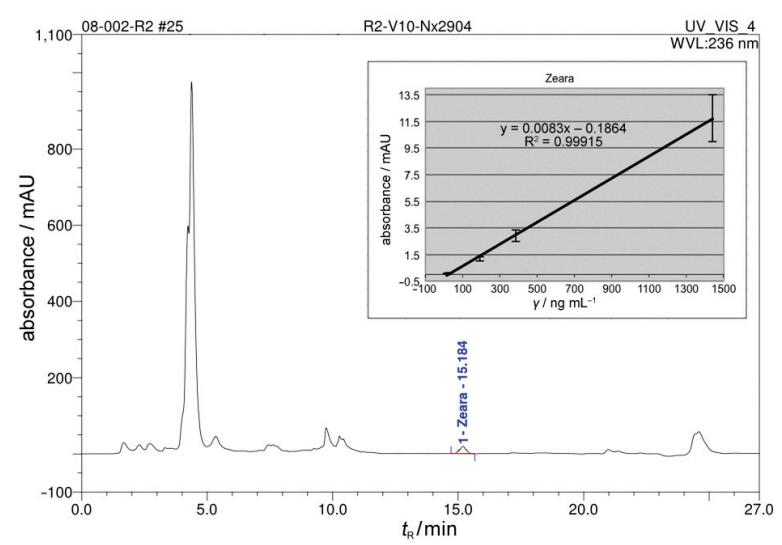

Figure 6. Overlaied chromatogram with calibration curve for zearalenone.

ditions of having the difference between the mean and the nominal concentration (bias) of the measured QC samples concentrations in between $\pm 15 \%$ for intra-day and between-days assay. The bias values obtained were from $-12.244 \%$ to $-2.67 \%$ in the intra-days assay and 
from $-12.244 \%$ to $11.546 \%$ in the between-days assay for aflatoxin B1, respectively from $-3.409 \%$ to $-1.716 \%$ in the intra-day assay and from $-4.733 \%$ to $10.415 \%$ in the between-days assay for ochratoxin A, and finally from $-5.35 \%$ to $8.056 \%$ in the intra-day assay and from $-5.35 \%$ to $11.991 \%$ in the between-days assay for zearalenone.

The method development for a better optimization of all the chromatographic factors, had to involve the best way for sample preparation during extraction process with ethyl acetate. There were also other solvents and even solvent mixtures that were tested to obtain a high and stable extraction for the full group of analytes that are present in a very complex biological mixture. Immunoaffinity columns for solid-phase extraction, but also different solvents for liquid-liquid extraction, like hexane, acetonitrile and even methanol is mentioned to be used for extracting mycotoxins, ${ }^{15,26}$ with recoveries between 65-90 \%. Considering the values obtained during the proposed simultaneous extraction procedure for the three selected mycotoxins, only pure ethyl acetate had acceptable and stable interaction and recovery, similar to the previously published ones.

After extraction process with an extraction factor of $\times 2.5$ the recoveries for the analytes of mycotoxin compounds were determined with the following values: aflatoxin $\mathrm{B} 1=64.56 \%$, ochratoxin $\mathrm{A}=66.95 \%$ and zearalenone $=38.21 \%$.

\section{CONCLUSION}

The validated method showed that a simple HPLC liquid chromatograph as modular system is capable to handle such a complex simultaneous determination of mycotoxins, and the quantification limits, although a simple UV detector for multiple channels was used, have reached the GLP requirements. The procedure for method optimization included the liquid-liquid extraction process and is settled longer to allow more samples to be analyzed and to check the status of the column after the washing stage for each injection. The recoveries of the analytes were $64.56 \%$ for aflatoxin B1, $66.95 \%$ for ochratoxin A and $38.21 \%$ for zearalenone, after the extraction process. Also, there was a good preconcentration $(\times 2.5)$ of the analytes and the internal standard, for their quantification, after the re-elution with small volumes of mobile phase. The quantification limits LOQ obtained by chromatographic parameter optimization, for each of the 3 mycotoxins were about $2.88 \mu \mathrm{g} \mathrm{kg}^{-1}$ for aflatoxin B1 and ochratoxin B, respectively $14.4 \mu \mathrm{g} \mathrm{kg}^{-1}$ for zearalenone in the raw biological material, making these values lower than those accepted by the actual European normatives and regulations ( 5 $\mu \mathrm{g} \mathrm{kg}^{-1}$ for aflatoxin $\mathrm{B} 1$ and ochratoxin $\mathrm{B}$, respectively $50 \mu \mathrm{g} \mathrm{kg}^{-1}$ for zearalenone in corn samples).
Acknowledgements. The method was developed through the project MAKIS AG no. 141560/22.04.2008, "Program complex de prevenire si combatere a infestarii cu miceti la cereale si plante furajere pentru asigurarea bunastarii animalelor si protectia consumatorilor", financed by the Romanian Ministery of Agriculture and The World Bank.

\section{REFERENCES}

1. Z. Dancea, M. Popa, M. V. Morar, A. Macri, I. Mihalca, and I. Buda, Rev. Med. Vet. 13 (3-4) (2003) 395.

2. I. Oroian, I. Oltean, M. Odagiu, L. Paulette, and I. Brasovean, Bulletin UASMV Agriculture 66 (2) (2009) 167-172.

3. H. M. Martins, M. M. Mendes-Guerra, and B. F. M. d'Almeida, Rev. Iberoam. Micol. 24 (1) (2007) 69-71.

4. G. N. Wogan, G. S. Edwards, and P. M. Newberne, Cancer Res. 31 (1971) 1936-41.

5. D. L. Thompson, J. O. Rawlings, M. S. Zuber, G. A. Payne, and E. B. Lillehoj, Plant Disaese 68 (6) (1984) 465-7.

6. M. L. Martins, H. M. Martins, and F. Bernardo, Rev. Port. Cien. Veter. 98 (548) (2003) 179-183.

7. P. Songsermsakui, G. Sontag, M. Cichna-Marki, J. Zentek, and E. Razzazi-Fazeli, J. Chrom. B, Analyt.Technol. Biomed. LifeSci. 843 (2) (2006) 252-261.

8. J. W. Dorner: Chromatographic Analysis of Mycotoxins, in: T. Shibamoto (Ed.), Chromatographic Analysis of Environmental and Food Toxicants, M. Dekker, NewYork, 1998. pp. 113-168.

9. L. W. Whitlow, D. E. Diaz, B. A. Hopkins, and W. M. Hagler, Alltech Inc. (2006).

10. M. Digrak and S. Ozcelik, Turk J. Biol. 25 (2001) 197-203.

11. A. Gunterus, L. V. Roze, R. Beaudry, and J. T. Linz, Food Microbiol. 24 (6) (2007) 658-663.

12. T. Igawa, N. Takahasi-Ando, N.Ochiai, S. Ohsato, T. Shimizu, T. Kudo, I. Yamaguchi, and M. Kimura, Appl. Environm. Microbiol. 73 (5) (2007) 1622-1629.

13. M. C. Spanjer, P. M. Rensen, and J. M. Scholten, Food Addit. Contam., Part A. 25 (4) (2008) 472-89.

14. J. Diana Di Mavungu, S. Monbaliu, M. L. Scippo, G. MaghuinRogister, Y. J. Schneider, Y. Larondelle, A. Callebaut, J. Robbens, C. Van Peteghem, and S. De Saeger, Food Addit. Contam., Part A 26 (6) (2009) 885-95.

15. M. W. Trucksess, C. M. Weaver, C. J. Oles, F. S. Fry, G. O. Noonan, J. M. Betz, and J. I. Rader, J AOAC Int. 91 (3) (2008) 511-523.

16. Y. Y. Hu, P. Zheng, Z. X. Zhang, and Y. Z. He, J. Agric. Food Chem. 54 (12) (2006) 4126-4130.

17. R. J. Garcia-Villanova, C. Cordón, A. M. González Paramás, P. Aparicio, and M. E. Garcia Rosales, J. Agric. Food Chem. 52 (24) (2004) 7235-7239.

18. A. Curticapean and S. Imre, J. Biochem. Biophys. Meth. 69 (2007) 273-281.

19. A. Curticapean, D. Muntean, M. Curticapean, M. Dogaru, and C. Vari, J. Biochem. Biophys. Meth. 70 (2008) 1304-1312.

20. http://www.chem.agilent.com/Library/applications/59893634EN.pdf (accessed August 10, 2006).

21. http://www.fermentek.co.il/ochratoxin_A.htm (accessed August 08, 2011).

22. http://www.fermentek.co.il/zearalenone.htm (accessed August 08, 2011).

23. Guidance for Industry, Bioanalytical Method Validation, U.S. Department of Health and Human Services, Food and Drug Administration, 66 (100) 2001.

24. OECD. The Applications of the GLP Principles to Short Term Studies, GLP Consenses Document, Environmental Monography, 99(23), 1999.

25. D. Garon, E. Richard, L. Sage, V. Bouchart, D. Pottier, and P. Lebailly, J. Agric. Food Chem. 54 (9) (2006) 3479-3484.

26. M. Canella and G. Sodini, U.S. Patent 4436756 Intl.Cl. A23L1/015, 13 March 1984. 